MATEC Web of Conferences 9, 05001 (2013)

DOI: $10.1051 /$ matecconf/20130905001

(C) Owned by the authors, published by EDP Sciences, 2013

\title{
Fire hazard analysis of façade systems in reconstructing buildings
}

\author{
Giletich Anatoly Nikolaevich ${ }^{1}$, Kosachev Andrey Arcad'yevich², \\ and Kosachev Andrey Andreevich ${ }^{3}$
}

\author{
${ }^{1}$ Deputy Director of Department of Supervision EMERCOM of Russia, Candidate of \\ Technical Sciences, Russia \\ 2 Deputy Chief of the Research Center of Fire Prevention, Head of Department, Candidate of \\ Technical Sciences, Russia \\ ${ }^{3}$ Assistant, Department of Complex Safety in the Moscow State University of Civil \\ Engineering, Russia
}

\begin{abstract}
In the article the real fires with façade systems have been examined, the causes of fire and the location of ignition sources have been considered. This analysis showed that fires occur during the mounting of façade systems. In this regard, a fire scenario in the reconstructing building has been considered, and a graphical report has been presented. The graphical report shows that in the event of fire in the office building with façade systems and smoke clear stairway marked as N1, a smoke free zone is blocked by the hazardous fire factors earlier than occupants are able to evacuate through it. So probability of safe and in time evacuation should be taken as equal to 0 in calculations, and therefore the value of fire risk exceeds the value that is specified in the existing fire safety standards.
\end{abstract}

Fire safety of buildings with vent facade systems is the most actual problem for the community of professionals nowadays.

The use of one or another construction in Russian Federation finally depends on its fire and technical characteristics that include fire resistance and class of fire hazard grade. Though systems of façade additional heat insulation are being researched in Europe, USA and Canada for about twenty years, there isn't unified coordinated agreement on the problem of how to evaluate the level of this hazard, and how to set norms the use of the system according to this level. At present the use of additional thermal protection of facades causes the problem of their fire safety and requires a comprehensive research that apparently results to correction or revision of the national fire safety requirements to exterior walls. It should be noted that the foreign standards don't contain such category as "class of fire hazard of building structures".

To provide reliable and fire safety exploitation façade systems with use of plaster and combustible heat insulation a number of recommendations should be strictly performed:

- edging of window and door openings should be always applied;

- non-combustible mineral wool hoards should be always applied as fire protection insets.

At the same time, available data on real fires that are presented in Table 1 indicate that all "remarkable" fires involving façade systems occur on the stage of installation.

On the base of the data from the Table 1, it seems to be logical to examine a design fire in a reconstructing building.

This is an Open Access article distributed under the terms of the Creative Commons Attribution License 2.0, which permits unrestricted use, distribution, and reproduction in any medium, provided the original work is properly cited. 


\section{MATEC Web of Conferences}

Table 1. Fire involving façade systems.

\begin{tabular}{|l|l|l|}
\hline Name of the unit: & Official cause of fire: & Location of the ignition source \\
\hline $\begin{array}{l}\text { Office building «Dookat Palace»; } \\
\text { address: 6, Gashek str., Moscow }\end{array}$ & $\begin{array}{l}\text { Failure in electric wiring of } \\
\text { building exterior lighting }\end{array}$ & Exterior of building \\
\hline $\begin{array}{l}\text { Non-occupied apartment house; } \\
\text { address: 10, Ivan Babushkin str., } \\
\text { Moscow }\end{array}$ & $\begin{array}{l}\text { Ignoring of safety requirements } \\
\text { during roofing fire work }\end{array}$ & Exterior of building \\
\hline $\begin{array}{l}\text { Business centre; } \\
\text { address: 38a, } 2^{\text {nd }} \text { Hootarskay } \\
\text { str., Moscow }\end{array}$ & $\begin{array}{l}\text { Ignoring of safety requirements } \\
\text { during electric welding }\end{array}$ & Exterior of building \\
\hline $\begin{array}{l}\text { Office building of Moscow } \\
\text { Center of Fighting Art; } \\
\text { address: } 118 / 1, \text { Varshavskoye } \\
\text { shosse, Moscow }\end{array}$ & $\begin{array}{l}\text { Ignoring of safety requirements } \\
\text { during electric welding }\end{array}$ & Exterior of building \\
\hline
\end{tabular}

The necessity of reconstruction may be prescribed by:

- state of town-planning market;

- increase of power efficiency level;

- increase of commercialization of buildings;

- standard requirements that regulate the frequency of periodic repair and reconstruction works.

The value of fire risk is a quantitative criterion determining that a required fire safety level at the unit is provided. In accordance with item 1 of clause 6 [1]:

"Fire safety of a protected unit is regarded as provided if it meets the following conditions:

1) fire safety requirements that are determined by the technical regulations adopted in accordance with the Federal Law "About Technical Regulation" are completely provided; and fire risk doesn't exceed permissible values that are presented in the given Federal Act; ${ }^{1}$

2) fire safety requirements that are determined by the technical regulations adopted in accordance with the Federal Act "About Technical Control" and requirements of fire safety codes are completely provided."

According to [3] the value of fire risk is calculated by the formula:

$$
Q_{\hat{a}, i}=Q_{n, i} \cdot\left(1-K_{a n, i}\right) \cdot P_{n p, i} \cdot\left(1-P_{\hat{y}, i}\right) \cdot\left(1-K_{n, \mathrm{c}, i}\right) .
$$

Where $Q_{n, i}$ - frequency of fire origin in a building during a year. If statistical information isn't available, the value $Q_{n}=4 \cdot 10^{-2}$ is permissible to use for each building.

$K_{a n, i}$ - probability of effective activation of automatic fire suppression system. The value of $K_{a n, i}$ is determined by an operational reliability of the system's units that are presented in technical documents. If data on operational reliability aren't available, the value $K_{a n, i}=0,9$ is permissible to use in the event that one of two conditions presented below is satisfied:

- building is equipped by an automatic fire suppression system that meets the fire safety standard requirements;

- according to fire safety standard requirements building isn't required to be equipped by an automatic fire suppression system

In the rest of cases $\mathrm{K}$ is taken to be equal to a zero;

${ }^{1}$ According to Federal Law No. 123 "About firesafety requirments" the value of individual fire risk must not exceed $10^{-6}$ per year. 


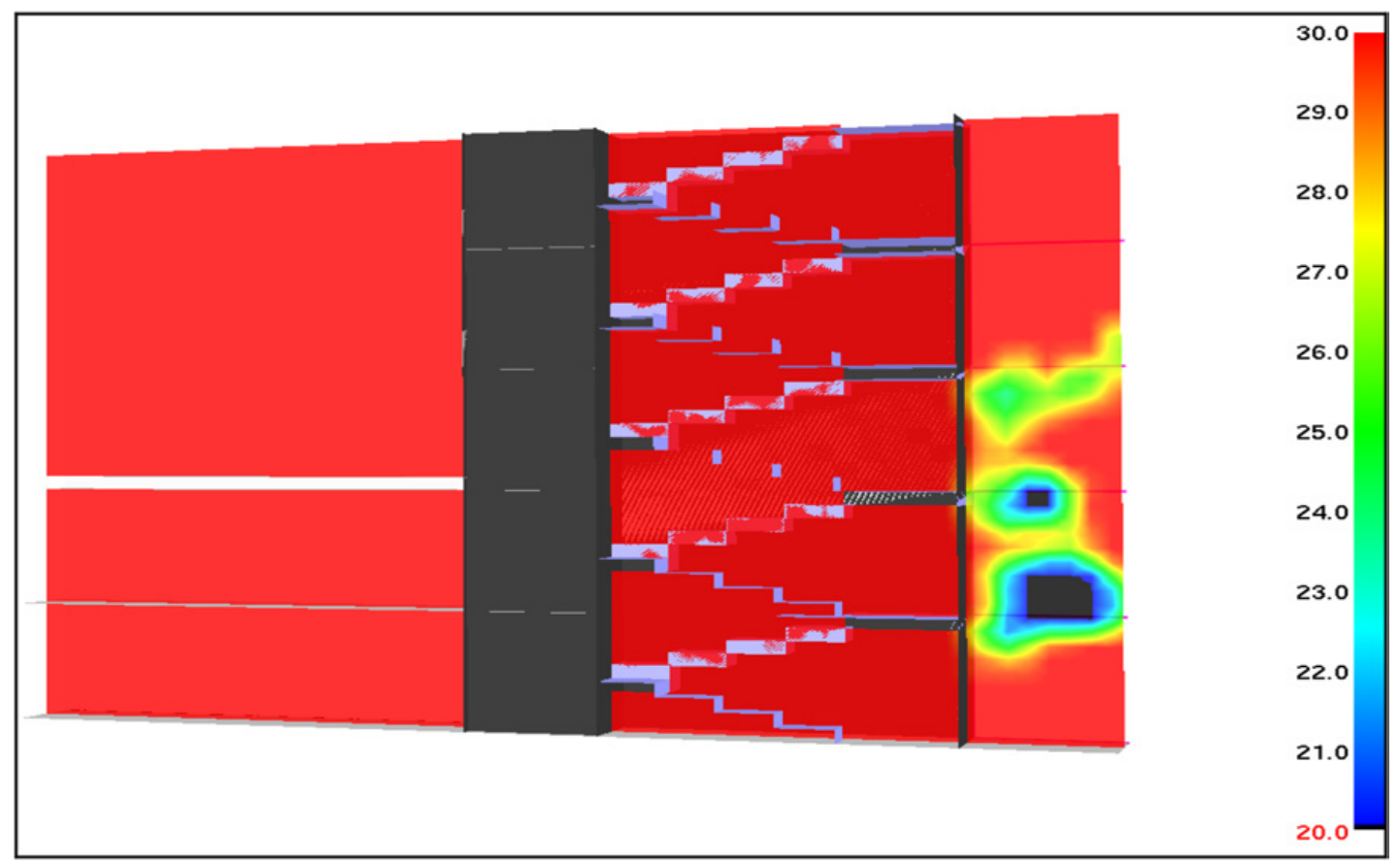

Figure 1. Smoke spread field in smoke protected stairway marked as N1 in 150 seconds after fire start.

$P_{n p, i}$ is a probability of the presence of occupants in a building that is determined in accordance with

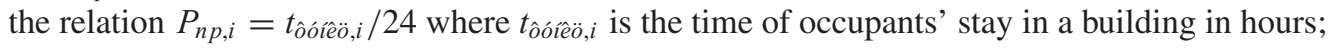

$P_{\hat{y}, i}$ is a probability of occupants' evacuation;

$P_{n, \zeta}$ is a probability of effective operation of fire protection system that is aimed at safe evacuation of occupants in case of fire;

$K_{n, c, i}$ is a coefficient determining that fire protection system aimed at safe evacuation of occupants in case of fire is brought in correspondence with fire safety standard requirements.

We believe that fire risk assessment for the buildings with use of façade systems on the stage of reconstruction is highly required due to technological process never stops. Moreover, legislation of Russian Federation defines fire risk assessment as mandatory part of design.

Fire hazard analysis of façade systems is a complex process that should consider different factors:

- ignition source;

- location of point of fire origin;

- variants of development of events;

- study of statistical data and real fires data involving façade systems;

- design features of façade systems and lot of the other factors.

When fire risk is calculated for a reconstructing building with the use of façade systems the most difficult problem is a determination of two values: a probability of occupants' evacuation $\left(P_{\hat{y}, i}\right)$ and a frequency of fire origin in a building during a year $\left(Q_{n, i}\right)$.

With relation to the examining problem it seems to be expedient to take into account the presence of façade systems during fire risk calculation in the following way:

1. Development of the Event Tree that consider a probability of fire origin in accordance with "Provision about a Periodic Preventive Maintenance", but not less than 1 time in 10 years. 


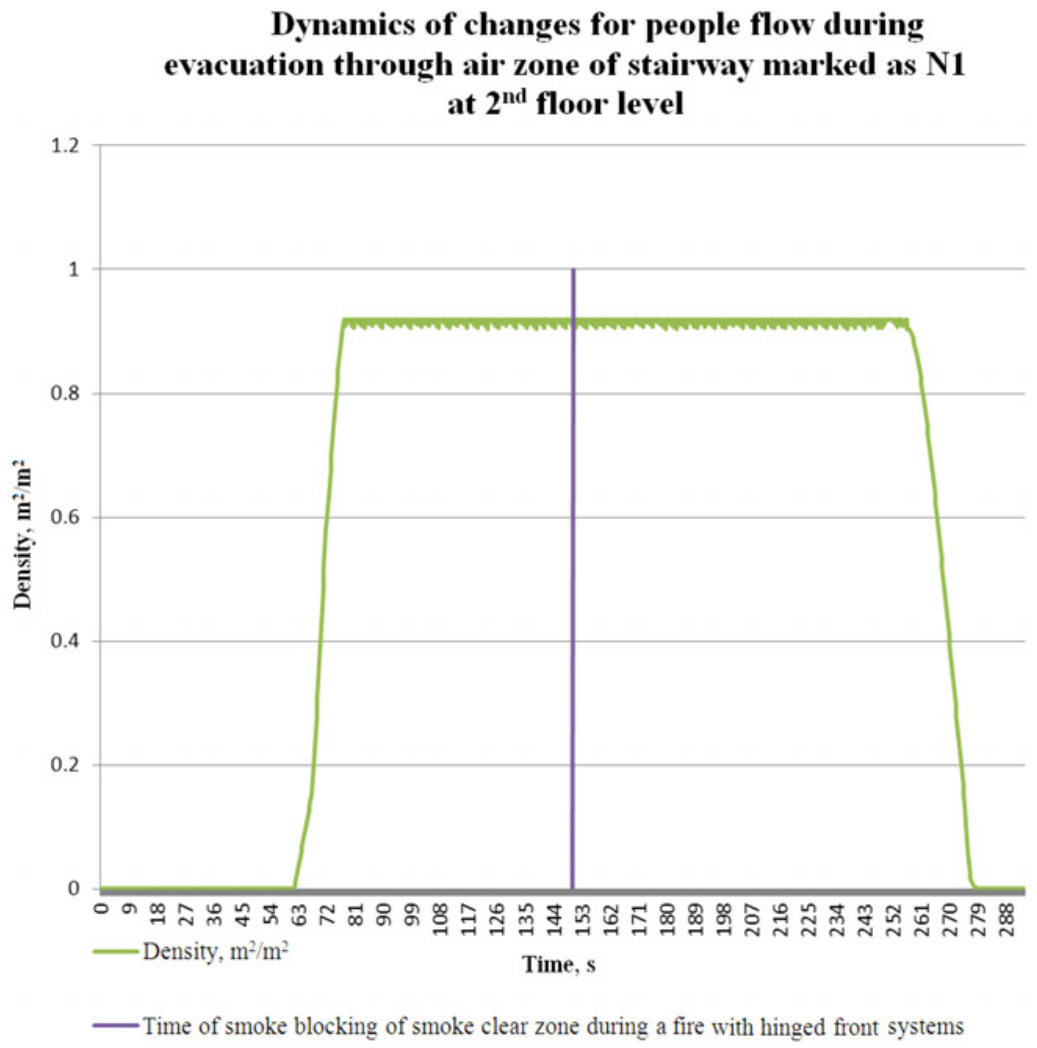

Figure 2. Dynamics of changes for people flow during evacuation through air zone of stairway marker as N1 at second floor level.

2. When a probability of occupants' evacuation is determined, the following initial data should be used:

- fire arises at the windward façade of a building;

- external fire arises at the 1-st (ground) floor that external walls are finished by façade system in accordance with design project;

- hydroprotection membrane should be considered as the main fire load;

- height of floor fire protection inset should be considered;

- time of window opening breaking should be taken according to a way of glazing and temperature conditions of design fire;

- an assumption is taken that energy of ignition source induces burning of façade systems;

- time for start of occupants' evacuation out of a building is taken according to an arrangement of fire alarm units and the Building Emergency Evacuation System but not less than 2 minutes.

According to the presented algorithm fire risk has been calculated for the office building with the underground parking situated in Moscow.

During the calculation it has been revealed that the dynamics of a fire arising on the outside of a building (ignition source is outside, on the façade system) doesn't permit to egress the building in proper time and in safe conditions through the smoke clear stairway marked as N1 due to smoke protected zone is blocked by the hazardous factors of fire.

The results of fire dynamics simulation are presented in Figures 1 and 2. 
In Figure 2 data comparison for calculated evacuation time and time of blocking by hazardous factors of fire is presented.

Calculation results revealed that $P_{\hat{y}}=0$ for the case of a fire with façade systems. Therefore value of fire risk will exceed the value $10^{-6}$ and it may be asserted that the unit doesn't satisfy the fire safety requirements.

\section{CONCLUSIONS}

To decrease the value of fire risk additional measures should be taken. In our opinion such measures may include:

- in the process of mounting work window openings and the other openings in external walls should be protected by non-combustible insets;

- to provide additional measures for protection of smoke free zones (balconies) of a smoke protected staircases. For example it could be temporary separating of these zones from open air. Another way - temporary ways of fresh air supply into the space of staircases.

\section{References}

[1] Federal Law No.190 of 29.12.2004 “Town-Planning Code of Russian Federation".

[2] Federal Law No.123 Federal Act “About Fire Safety Requirements" of 22.07.2008 in redaction of Federal Law No.117 of 10.07.2012.

[3] Procedure approved by the Order No.382 of the Ministry of Russian Federation for Civil Defense, Emergencies and Elimination of Consequences of Natural Disasters of 30.06.2009 in redaction of the Order No.749 of the Ministry of Russian Federation for Civil Defense, Emergencies and Elimination of Consequences of Natural Disasters of 12.12.2011.

[4] Regulation of the Government of Russian Federation of 16.02.2008 No.87 "About the Composition of the Divisions of the Project Documentation and the Requirements to their Content". 